\title{
VULNERABILIDADE SOCIAL E OFERTA DE SERVIÇOS PÚBLICOS NO MUNDO RURAL. DUAS MOEDAS E UMA SÓ FACE?
}

\author{
Felipe Mattos Monteiro* \\ Rafael da Silva** \\ Erni Jose Seibel ${ }^{* * *}$
}

\begin{abstract}
Resumo
Neste artigo buscamos analisar a vulnerabilidade social e a oferta de serviços públicos no mundo rural. O processo de globalização produziu a realocação da oferta de serviços públicos básicos (essencialmente educação, saúde e saneamento) entre os agentes produtores (Estado e mercado) introduzindo padrões de acesso seletivo, precário e excludente (re) produzindo zonas de vulnerabilidade. A vulnerabilidade social implica na fragilização da estrutura familiar, comunitária e institucional frente às ações de ameaças externas, complexidades tecnológicas e informacionais; capacidade para manter-se no mercado; desequilibrio nas relações de gênero, envelhecimento populacional e debilitação das comunidades, entre outros. A oferta de serviços públicos fica marcada pela sua ausência ou pela sua concentração em espaços urbanos, principalmente aqueles direcionados à proteção familiar e comunitária tais como: saúde e educação (os mais solicitados); comunicação; e saneamento. A base de dados foram o Censo Populacional e Censo Agropecuário (IBGE), assim com o Levantamento Agropecuário/SC (LAC). Os resultados da pesquisa revelaram que as regiões Serrana e Norte catarinense são as mais frágeis quanto à oferta de serviços públicos. Já as regiões do Vale do Itajaí, Grande Florianópolis e sul catarinense apresentam um relativo equilíbrio regional apesar de em todas ser frágil o saneamento básico. Considerando a associação entre IOSP/Básico e a variação demográfica constatamos que municípios com bom índice de oferta de serviços públicos (IOSP) experimentaram variação positiva na população. Destacamos uma crescente debilidade das comunidades rurais, com crescente aumento de desconfiança entre os moradores associado com o sentimento negativo de apoio institucional em caso de proteção social.
\end{abstract}

Palavras-chave: vulnerabilidade social, serviços públicos, mundo rural.

\footnotetext{
* Graduado em Ciências Sociais pela Universidade Federal de Santa Catarina. Mestrando em Sociologia Política pela UFSC. É membro ah doc do NIPP - UFSC (Núcleo Interdisciplinar em Políticas Públicas). Atualmente é assistente de análise quantitativa da Empresa de Pesquisa de Mercado e Opinião Pública Market Analysis Brasil, sediada em Florianópolis.

** Formado em História pela PUC/RJ, especialista em História do Brasil pela PUC/MG, especialista em Psicologia da Educação pela PUC/MG e mestre em Educação pela PUC/RJ. Professor universitário e assessor de secretarias municipais de educação no estado de Santa Catarina há dez anos.

*** Doutor em Ciência Política pela Freie Universität Berlin, professor do Departamento de Sociologia e Ciência Política da UFSC e do Programa de Pós-Graduação em Sociologia Política. É vinculado à linha de pesquisa Ideias Instituições e Práticas Políticas; coordena o NIPP/Núcleo Interdisciplinar em Politicas Públicas, assim como projetos de pesquisa e extensão na área da políticas publicas.
} 
${ }^{1}$ A este respeito, veja Wacquant (2001).

${ }^{2}$ Referimo-nos aqui a certas ideias bastante claras e sedimentadas para o espaço social urbano e ainda confusas quando se pensa o mundo rural, tais como o conceito de vulnerabilidade social no âmbito familiar ou então a oferta de serviços públicos, tais como saneamento básico, principalmente coleta de lixo, que no ambiente rural tem uma perspectiva diferenciada.

${ }^{3}$ A este respeito veja Seibel (2004).

${ }^{4}$ Citamos como exemplo o surgimento de formas de violência urbana, como roubos das propriedades rurais e que produz sentimento de falta de confiança na comunidade.

\footnotetext{
${ }^{5}$ Propositalmente excluímos aqui os fatores de debilidade da propriedade agrícola, atenção e objeto histórico de políticas públicas de recorte produtivista.
}

${ }^{6}$ Ver Seibel (2001).
A proposta deste artigo é analisar dois fatores que adquiriram relevância no debate sobre políticas públicas na década de 1990, quais sejam, a vulnerabilidade social e a oferta de serviços públicos. No contexto da década o processo de globalização produziu transformações estruturais seja no âmbito da proteção social seja na oferta de serviços públicos e que eclodiram em formas inéditas de exclusão social. A realocação da oferta de serviços públicos básicos (educação, saúde e saneamento) entre os agentes produtores (Estado e mercado) introduzindo padrões de acesso seletivo, precário e excludente produzindo zonas de vulnerabilidade (CASTEL, 2004). Ambos fatores, fortemente relacionados, experimentam pari passu a transformação nas suas lógicas de concepção e gestão. Assim como a oferta de serviços públicos é inserida no espectro de uma racionalidade mercantil, sob balizamento regulatório, a proteção social é transformada em condição de ajuda, derivando a questão social com prática compensatória e filantrópica ou então, criminalizando-a, ao fixá-la como objeto de segurança publica. ${ }^{1}$

No que se refere ao mundo rural, estas questões sempre apareceram de forma secundária no debate e produção de concepções sobre vulnerabilidade social e serviços públicos, pois sempre tiveram o espaço urbano como referência. Isto nos impõe alguns limites de ordem metodológica, uma vez que a base de dados deste artigo é quantitativa. ${ }^{2}$

São crescentes e cada vez mais complexas as formas que assumem a exclusão e a vulnerabilidade social. O êxodo rural é o fenômeno mais drástico da exclusão social rural. O êxodo, expressão de uma "população sobrante" (CASTEL, 2004, p. 254) é historicamente impulsionado pelo fracionamento e perda da terra, pela ausência e ineficácia da política fundiária, pela construção de barragens, por limitações ambientais, desastres naturais, assim como a baixa renda da propriedade, o baixo nível (ou ausência) de oferta de serviços públicos, seguidos de fatores de ordem particular. ${ }^{3}$

Assim, a identificação e análise dos fatores que aceleram a vulnerabilidade social e a dinâmica da oferta de serviços públicos torna-se o principal objeto deste texto. A vulnerabilidade social implica na fragilização da estrutura familiar, comunitária e institucional frente a ações de ameaças externas, ${ }^{4}$ complexidades tecnológicas e informacionais; capacidade para manter-se no mercado; desequilíbrio nas relações de gênero, envelhecimento populacional e debilitação das comunidades, entre outros. $^{5}$ A oferta de serviços públicos fica marcada pela sua preponderante ausência ou pela sua concentração em espaços urbanos, principalmente aqueles direcionados à proteção familiar e comunitária tais como: saúde e 
educação (os mais solicitados); comunicação e saneamento básico. ${ }^{6}$

Buscamos aqui identificar os fatores de vulnerabilidade social rural pari passu a identificação da oferta de serviços públicos no mesmo contexto. $\mathrm{Na}$ primeira questão enfrentamos um desafio metodológico. A princípio, pretendíamos construir um índice de vulnerabilidade social rural quando nos deparamos com um limite na oferta de dados. Os censos produzidos na última década e que incluem o mundo rural (Censo Populacional e Censo Agropecuário) expressam, essencialmente a vulnerabilidade da propriedade familiar, na sua condição econômica e produtivista. ${ }^{7} \mathrm{~A}$ base de dados mais completa à disposição para este tipo de análise é o LAC (Levantamento Agropecuário) produzido pela Secretaria de Agricultura do Estado de Santa Catarina entre os anos de 2003 e 2004 e que atingiu a totalidade das propriedades rurais do estado. Este verdadeiro censo oferece dois blocos de informações muito úteis para inferirmos os fatores de vulnerabilidade social rural, quais sejam, a evasão rural e a participação institucional.

No que se refere à oferta de serviços públicos, a disponibilidade de dados já nos permite a produção de um índice (IOSP- Índice de Oferta de Serviços Públicos). Este trabalho vem sendo organizado pelo Núcleo Interdisciplinar em Políticas Públicas (NIPP) desde 1999. Compõe este índice três subíndices: saúde, educação e saneamento. Será a partir deste procedimento metodológico que classificaremos e analisaremos a distribuição de serviços públicos básicos em Santa Catarina. Para destacar o mundo rural selecionamos os municípios catarinenses com até 20 mil habitantes e que expressam esta condição. ${ }^{8}$

\section{Vulnerabilidade social}

Consideramos a ideia de exclusão um conceito amplo, relacionado a processos de discriminação ou enfraquecimento dos grupos sociais e à sua capacidade de reação. Intrínseco à ideia de exclusão inserem-se várias formas de segregação e discriminação social levando a um conjunto de vulnerabilidades difíceis de superar.

No campo das Ciências Sociais a contribuição mais densa para este debate tem sido de Robert Castel (2004). Este autor alerta para a diversidade de situações de exclusão no mundo atual e à necessidade do uso controlado desta noção. Para o autor, na maior parte dos casos, a exclusão traduz formas de degradação social relacionadas à situações como o emprego precário, se considerada a situação histórica de emprego estável. Castel (2004) distingue diferentes zonas da vida social povoadas por grupos sociais afetados por formas de carência, de priva-
${ }^{7}$ Mesmo incluindo dados sobre os responsáveis pela propriedade, os mesmos não tinham, necessariamente, a característica de vulnerabilidade social rural. Por exemplo, "número médio de anos de estudo do responsável pela família" um indicador de alcance limitado e discutível para este universo social.

${ }^{8}$ Orientamo-nos aqui pela definição de município rural sugerida por Wanderley Baudel (1997). 
ção material, de segregação, de discriminação e de vulnerabilidade e os define, metaforicamente, como zona de integração, zona de vulnerabilidade, zona de desvinculação e zona de desfiliação. $\mathrm{O}$ indivíduo pode estar inserido completamente nos dois primeiros casos, como pode estar inserido num e noutro não. Significa que aquele que está desvinculado da esfera do trabalho sofre maiores consequências do que aquele desvinculado apenas da área familiar, pois o seu sustento e o de sua família, sua participação na comunidade, assim como todo o funcionamento das relações sociais e da cidadania estão baseados na sua inserção ocupacional. A zona de vulnerabilidade se refere à precariedade do trabalho e à fragilidade relacional. $\mathrm{Na}$ zona de desvinculação, ou desfiliação, o indivíduo se encontra sem trabalho e em isolamento social.

Kowarick (2001) analisa a evolução do debate acerca da vulnerabilidade socioeconômica nos Estados Unidos e na França, e sobre a realidade brasileira. No caso dos Estados Unidos destaca a preponderância ideológica no conteúdo dos argumentos das vertentes que analisam a questão, assim como a produção de estigmas, nos quais os indivíduos acabam sendo culpabilizados pela sua própria condição de pobreza e miséria. A característica mais forte do caso francês remete ao fenômeno da desfiliação funcional e comunitária. Destaca, porém que a tradição republicana francesa prioriza a responsabilidade e a interferência estatal, diferentemente do caso americano. Referindose ao caso brasileiro Kovarick (2001) identifica, diferentemente dos casos americano e francês, o estigma da naturalização da miséria e da vulnerabilidade social. A opinião pública considera que a ação pública é historicamente inoperante, ineficaz, corrupta, falida, cujas funções deveriam ser reduzidas e substituídas por agentes privados mais capacitados para enfrentar as várias manifestações da marginalização social e econômica. Em consequência dessa argumentação, abre-se espaço para um amplo e diverso processo de desresponsabilização do Estado em relação aos direitos de cidadania e, no seu lugar, ampliam-se ações de cunho filantrópico que tendem a equacionar as questões da pobreza em termos de atendimento particularizado, setorializado e local. Na contramão dessa tendência avança a pressão social por políticas de segurança pública que, no senso comum, sugere a criminalização da miséria.

Como se manifesta a vulnerabilidade social no mundo rural? Será que é possível nesta esfera social utilizarmos as mesmas categorias propostas por Castel (2004) distinguindo os grupos sociais do mundo rural por formas diferenciadas de carência, de privação material, segregação, discriminação e vulnerabilidade? É importante considerar que a reflexão de Castel (2004) tem por base o declínio do Welfare State, especialmente a precarização do emprego e as formas de exclusão social que irromperam a partir desta condição estrutural. 
No que se refere à ideia de vulnerabilidade, objeto deste artigo e dos recursos metodológicos que utilizamos, basicamente quantitativos, defrontamo-nos com algumas questões. Primeiro, como qualificar os conceitos acima referidos para o mundo rural? Isto requer um debate epistemológico sobre a produção de indicadores. Segundo, não existe uma produção sistemática, significativa e específica de dados (basicamente do IBGE) sobre o perfil social, a condição, a familiar e comunitária do mundo rural. ${ }^{9}$ Os dados disponíveis são bem mais escassos que os do universo urbano. ${ }^{10}$ Os recortes metodológicos apresentados na literatura se referem à vulnerabilidade urbana ao mesmo tempo em que os estudos sobre a situação do mundo rural remetem à vulnerabilidade econômica da propriedade. Finalmente, destacamos que o aporte maior de políticas públicas é orientado para viabilizar economicamente a propriedade familiar, muito mais do que para propor proteção social à família e à comunidade. Políticas públicas e vulnerabilidade social são duas faces da mesma moeda. A evasão rural é, talvez, o registro mais explícito desta vulnerabilidade, assim como a ausência de políticas públicas. Estes dois fatores podem ser determinantes na dinâmica de expulsão, assim como atração no movimento migratório.

Centramos nosso trabalho na análise destas duas dimensões, a vulnerabilidade social e a oferta de serviços públicos. Dadas as circunstâncias metodológicas acima colocadas, o fator vulnerabilidade será antes um "garimpo das evidências" mais do que um estudo sistemático. Já a oferta de serviços públicos, pela disposição de dados, terá um formato mais ordenado.

\section{A oferta de serviços públicos para o mundo rural}

Três fatores influenciaram fortemente a oferta de serviços públicos no Brasil, a partir da Constituição de 1988. São eles: o acesso universal à proteção social, fixado pela condição de direito e cidadania; o processo de municipalização e o processo de privatização de empresas, órgãos públicos prestadores de serviços públicos.

De acordo com Souza (2005), duas estratégias estiveram presentes no processo constituinte. A primeira previa a abertura à participação popular, e a segunda previa a promoção da distribuição tributária para os municípios e estados. O processo de produção de políticas públicas envolveu vários atores de decisão (sociedade civil, entidades privadas, partidos políticos, mídia), embora suas ações viessem a ser materializadas pelos governos. A descentralização administrativa se tornou umas das principais políticas públicas do Estado brasileiro. Tendo sofrido constante pressão dos movimentos sociais, as demandas

\footnotetext{
${ }^{9}$ Talvez uma exceção seja as pesquisas sobre gênero no mundo rural, mesmo assim a grande maioria utiliza outros recursos metodológicos que não os quantitativos.

${ }^{10}$ Claro que essa afirmação não se aplica a estudos de caráter demográfico ou sobre as correntes migratórias, mas sobre as condições sociais da vida rural, os dados não permitem mais do que estudos de perfil social.
} 
${ }^{11}$ Neste sentido, os municípios passavam a desempenhar um novo papel em relação à agenda pública. Muitos serviços foram repassados para as entidades subnacionais, como é o caso da educação fundamental e infantil, alguns serviços de saneamento básico, entre outros.

${ }^{12}$ Enquanto a participação dos municípios na renda total da União era de 9,5\% em 1980, em 1992 este número aumentava $16,9 \%$, quatro anos após a promulgação da Constituição. Os governos estaduais também obtiveram um grande acréscimo, de $24,3 \%$ passaram para $31,0 \%$ (MELO, 1996).

\footnotetext{
${ }^{13}$ Inicialmente vamos transpor aqui o debate sobre a definição de rural, assumindo a proposta de Wanderley Baudel (1997) que define as cidades com até 20 mil habitantes como nãourbanas. As razões apontadas por Wanderley Baudel estão fortemente vinculadas ao debate que aqui propomos por tomar como parâmetro fatores de ordem político-administrativas. A autora parte do pressuposto de que é o rural brasileiro que mais necessita de políticas públicas e de ações de desenvolvimento local, está preponderantemente localizado nos municípios com menos de 20 mil habitantes.
}

${ }^{14}$ Para Melo (1996), as razões da emancipação estariam ligadas a três fatores. $\mathrm{O}$ primeiro diria respeito à participação de novas unidades políticas na distribuição do Fundo de Participação dos Municípios. Outro motivo esta ligada à ausência de serviços públicos essenciais nas localidades. Os recursos, bem como as ações políticas das esferas superiores de governo, ficam centralizados na sede municipal. A emancipação seria uma estratégia da localidade para se inserir no sistema federativo. Finalmente que os eleitores dos distritos são favoráveis à emancipação por saberem que a carga tributaria local não aumentará. por serviços e poderes descentralizados ampliaram a agenda pública no âmbito da Constituição de $1988 .{ }^{11}$ Esta estratégia justificava-se no sentido de que cada bem público deveria ser provido pelo nível de governo, o qual, possibilitaria melhores condições de atendimento ao grupo social necessitado do serviço. ${ }^{12}$

Até a década de 1980 se podia afirmar com segurança que a quase totalidade de serviços públicos básicos ofertados para a população (saúde, educação, saneamento etc.) eram organizados e prestados por órgãos e empresas estatais (municipais, estaduais e federais). Na década de 1990 acontece uma variação radical na esfera de oferta de serviços públicos deslocando para o mercado a sua produção. Entra em cena uma nova concepção de função regulatória associada ao processo de privatização de empresas públicas prestadoras de serviços. O marco regulatório funda uma nova perspectiva de vínculo entre Estado, mercado e sociedade civil implicando num jogo de correlação de forças até então inédito no cenário político-institucional do país.

Argumentando a respeito do conceito de rural e urbano e o tamanho das cidades, Wanderley (1997) pressupõe que a cidade estaria normalmente identificada como depositária do poder público e distributiva dos serviços públicos e privados. O povoamento rural, mais rarefeito e disperso, não ficaria, portanto, inscrito na estrutura político-administrativa, nem absorveria os serviços essenciais. ${ }^{13}$ São as cidades que sediam a representação do estado e concentram os serviços, enquanto o rural supõe a ausência do poder público no seu espaço e mesmo a ausência da grande maioria dos bens e serviços naturalmente concentrados na área urbana. A vida da população rural depende, portanto, direta e intensamente, do núcleo urbano que a congrega para o exercício de diversas funções e o atendimento de diversas necessidades econômicas e sociais. Consiste assim, num espaço de precariedade social. Seu habitante deve sempre se deslocar para a cidade se quer ter acesso ao posto médico, ao banco, ao Poder Judiciário e até mesmo à igreja paroquial. Se a pequena aglomeração cresce e multiplica suas atividades, o meio rural necessariamente não se fortalece e, em consequência, resulta, frequentemente, na sua ascensão à condição de cidade, brevemente sede do poder municipal. ${ }^{14}$ Neste contexto a única alternativa que existe para a população rural se resume em permanecer periférica ou tornar-se urbana através da expansão do próprio espaço rural, ou então, o êxodo para as cidades (WANDERLEY, 1997).

Wanderley (1997, p. 5) afirma que é necessário considerar as relações que se estabelecem entre o meio rural e a cidade próxima, sede municipal, da qual ele é entorno. Estas relações definem um espaço social, diversificado que é preciso apreender e compreender, e que resulta da própria diferenciação das cidades, das estratégias dos habitantes do 
campo, de acesso aos bens e serviços municipais e da diferenciação dos espaços da vida cotidiana. Esta diferenciação gera pelo menos três tipos de relações entre o rural e o urbano, a saber:

- Os casos em que a população do campo é excluída dos bens e serviços, concentrados na cidade, sejam porque esta é muito distante dos locais de moradia dos rurais, seja porque estes têm poucos meios de locomoção.

- Os casos em que os municípios como um todo, pela sua reduzida dimensão, não têm capacidade para abrigar os bens e serviços dos quais deveria ser depositário.

- Os casos em que, na busca dos bens e serviços de que necessita, a população do campo apropria-se da sede municipal como um espaço que lhe pertence, seja frequentando-a com regularidade, seja, inclusive, instalando na cidade seu lugar de residência mesmo quando mantém todos os seus vínculos de trabalho no meio rural.

Para Wanderley (1997), o rural deve constituir-se como um objeto legítimo e pertinente de interferência dos poderes públicos. Os conceitos adotados pela legislação brasileira ao esvaziar artificialmente o mundo rural, o desqualificam enquanto prioridade para políticas públicas.

\section{IOSP (Índice de Oferta de Serviços Públicos)}

Em 1970, a população catarinense que vivia em municípios com até 20 mil habitantes era 1.429 .439 habitantes, o que perfazia $50,0 \%$ da população total, dividida em 162 municípios. Isto significa que 82,2\% dos municípios catarinenses eram de natureza rural. Em 2006 Santa Catarina possuía 293 municípios, sendo que 81,2\% com população igual ou menor a 20.000 habitantes onde vivia 29,6\% da população catarinense (www.ibge.gov.br).

Para analisar a oferta de serviços públicos no mundo rural organizamos um índice (IOSP), composto por três subíndices: IOSP/ Educação, IOSP/Saúde, IOSP/Saneamento e 30 indicadores ${ }^{15}$.

O recurso da análise por região e tamanho de municípios permite observar a desigualdade na distribuição e tendências segundo características regionais, assim como a oferta por capacidade administrativa. O quadro 1 revela que as regiões Serrana e Norte catarinense são as mais frágeis quanto à oferta de serviços públicos. Apesar da exceção em saneamento básico na região serrana, a área da saúde é a que expressa maior desigualdade em relação ao estado. Já as regiões do Vale do Itajaí, Grande Florianópolis e sul catarinense apresentam um relativo equilíbrio regional apesar de, em todas ser frágil o item saneamento básico. Em Monteiro (2006), constatase que a maior fragilidade na oferta de serviços de saneamento básico encontra-se nos municípios com mais de 100 mil habitantes.
${ }^{15}$ Saúde (estabelecimentos de saúde públicos, privados, postos de trabalho de médicos, enfermeiros e odontólogos, leitos hospitalares); Educação (número de matrículas; número de docentes, estabelecimento pré-escola, fundamental, ensino médio, público/privado; municipal, estadual). Saneamento -Número de veículos e equipamentos utilizados nos serviços de limpeza urbana e/ou coleta de lixo; Extensão da rede de drenagem urbana; Número de entidades prestadoras de serviços de limpeza urbana e/ou coleta de lixo; Número de estações de tratamento; Número de ligações de água; Extensão da rede distribuidora; Extensão de rede distribuidora, (MATTOS MONTEIRO, 2006). 
Quadro 1: IOSP/Educação, Saúde, Saneamento Básico e Básico por mesorregiões

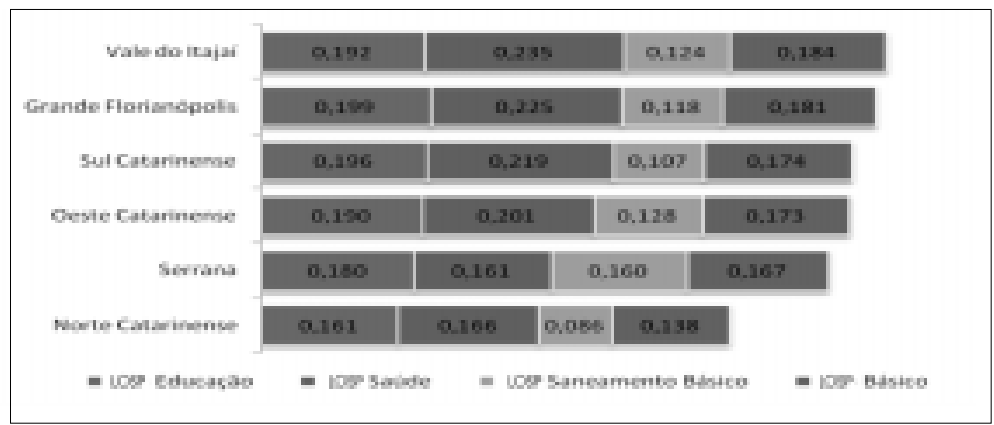

Fonte: IBGE; elaboração: NIPP.

Quanto ao tamanho de municípios destaca-se entre aqueles com até 20 mil habitantes um perfil regular na área da educação, crescente na área da saúde e decrescente no campo do saneamento. Entre os municípios de tamanho médio, isto é, entre 20 e 50 mil, uma inversão de tendência positiva quanto à educação, negativa quanto à saúde e estável quanto ao saneamento. Já entre os municípios grandes o destaque é a área da saúde em sentido positivo e saneamento em termos negativos. Alguns destes dados expressam um senso comum quanto às áreas e tamanho: a) uma relativa regularidade na educação considerando políticas federais; b) oferta de saúde em municípios maiores em função das classificações do SUS por complexidade de procedimento; e baixos índices de saneamento à medida que aumenta o tamanho em função do alto custo e de ausência de políticas públicas bem como de um marco regulatório para o setor.

Quadro 2: IOSP/Educação, Saúde, Saneamento Básico e Básico por tamanho de municípios

\begin{tabular}{|c|c|c|c|c|}
\hline Mals de $109 \mathrm{mi}$ & 0.244 & 0.256 & D.06: & 0.197 \\
\hline Utese de 50 a 100 mi & 0,242 & 0.255 & 0,060 & 0.194 \\
\hline Min de 40 a 50 mi & 0,156 & 0.154 & 0,068 & 0,140 \\
\hline Mois de 30 a s0 mi & 0.231 & 0.204 & 0.073 & 0.169 \\
\hline Mavis dia 20 a $30 \mathrm{mi}$ & 0.236 & 0.222 & 0.075 & 0.177 \\
\hline Mos do 10 a $20 \mathrm{mi}$ & 0,181 & 0.212 & 0,047 & 0,160 \\
\hline Mas de 5 a $10 \mathrm{mi}$ & 0.194 & 0.299 & 0.108 & 0.170 \\
\hline \multirow[t]{2}{*}{$2006 \mathrm{mal}$} & 0.195 & 0,187 & 6,156 & 0,160 \\
\hline & $\begin{array}{l}=105 \mathrm{ED} \\
=105 \mathrm{SA}\end{array}$ & BAsico & $\begin{array}{l}\text { IOSP SAUD } \\
\text { IOSP - Bde }\end{array}$ & \\
\hline
\end{tabular}

Fonte: IBGE; elaboração: NIPP. 
$\mathrm{Na}$ tabela 1, associamos tamanho do município e variação REVISTA GRIFOS 101 populacional. Dividimos os municípios com população inferior a 20 mil habitantes em 8 categorias, tendo como critério o tamanho da população, como podemos observar na tabela 1 . Notamos que os municípios que tiveram consideráveis decréscimos na sua população concentram-se principalmente no grupo com até 5 mil habitantes. A partir deste tamanho a inflexão é progressiva.

Tabela 1: Variação demográfica por tamanho de município

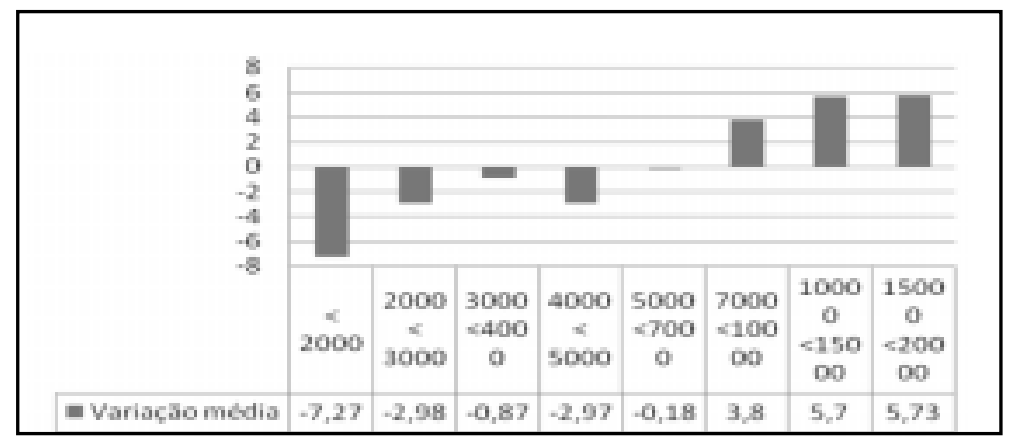

Fonte: Contagem da População 2007/IBGE (Processamento NIPP/UFSC).

Analisando a idade dos municípios pode-se perceber que houve dois grandes movimentos emancipatórios recentes em Santa Catarina, um nos anos 1950-1960 e outro nos anos 1990, do qual resultaram dois agrupamentos de municípios por idade. O primeiro grupo com 91 municípios e idade média de 15,8 anos, e o segundo, somando 144 municípios, com idade média de 53,8 anos. No diagrama 1 analisamos a tendência entre variação populacional e idade dos municípios com até 20 mil habitantes. Podemos perceber a tendência nos municípios com até 24 anos de variação populacional positiva. Em contrapartida, nos municípios acima de 24 anos apresentam uma tendência negativa de variação populacional, o que equivale afirmar que entre os municípios com até 20 mil, os mais antigos têm capacidade menor de retenção populacional (ver diagrama 2). ${ }^{16}$

${ }^{16}$ Não estão computados aqui os índices de crescimento vegetativo. 
Diagrama 1: Variação populacional versus idade do município (até 24 anos)

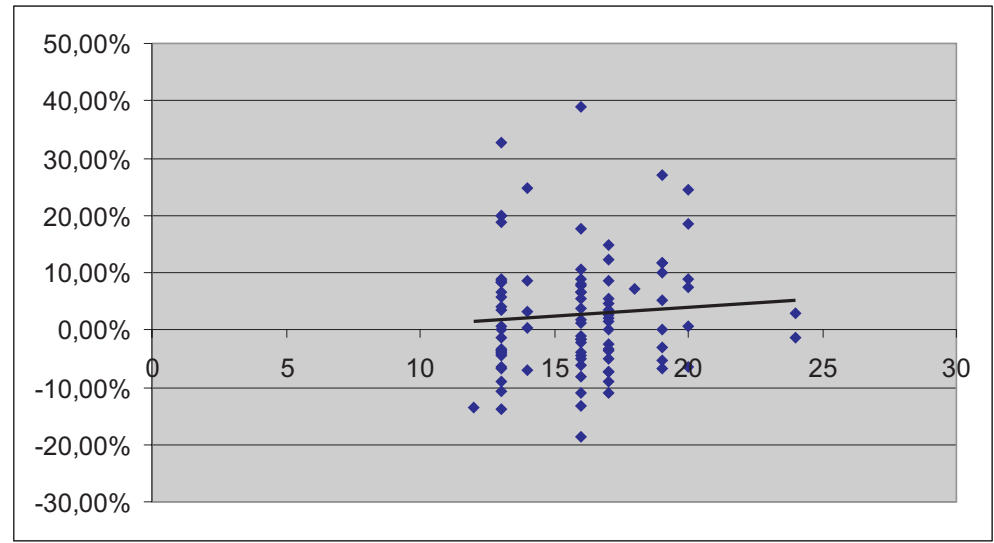

Fonte: Contagem da população 2007/IBGE (Processamento NIPP/UFSC).

Diagrama 2: Variação populacional versus idade do município (acima de 24 anos)

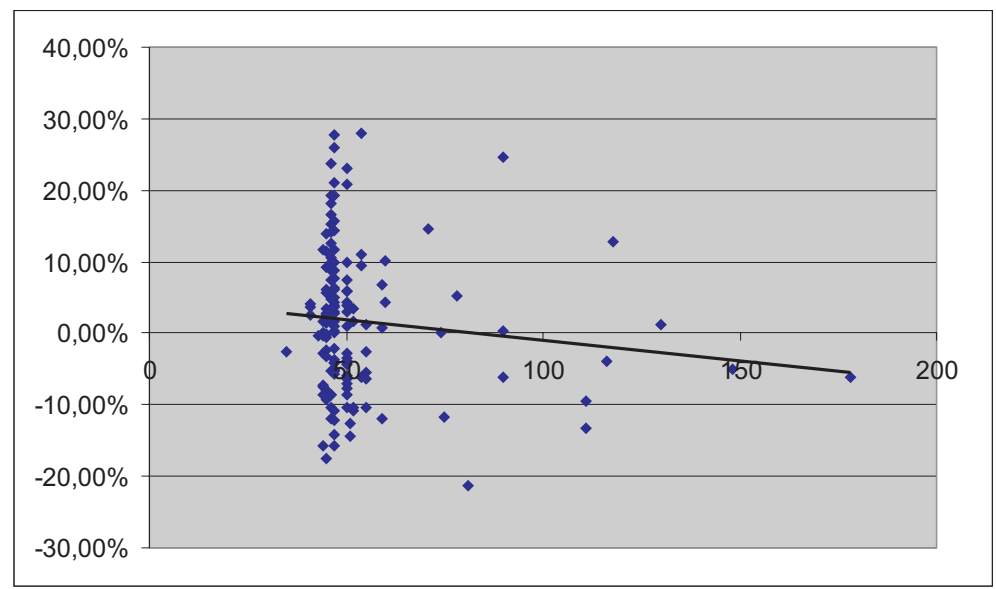

Fonte: Contagem da população 2007/IBGE (Processamento NIPP/UFSC).

Associando o IOPS/Básico e a variação demográfica, podemos observar no diagrama 3 que há uma tendência positiva entre as variáveis IOSP/Básico e a variação demográfica, ou seja, municípios com bom índice de oferta de serviços públicos experimentaram variação positiva na população. 
Diagrama 3: IOSP/Básico X Variação demográfica em municípios com população inferior a 5 mil habitantes

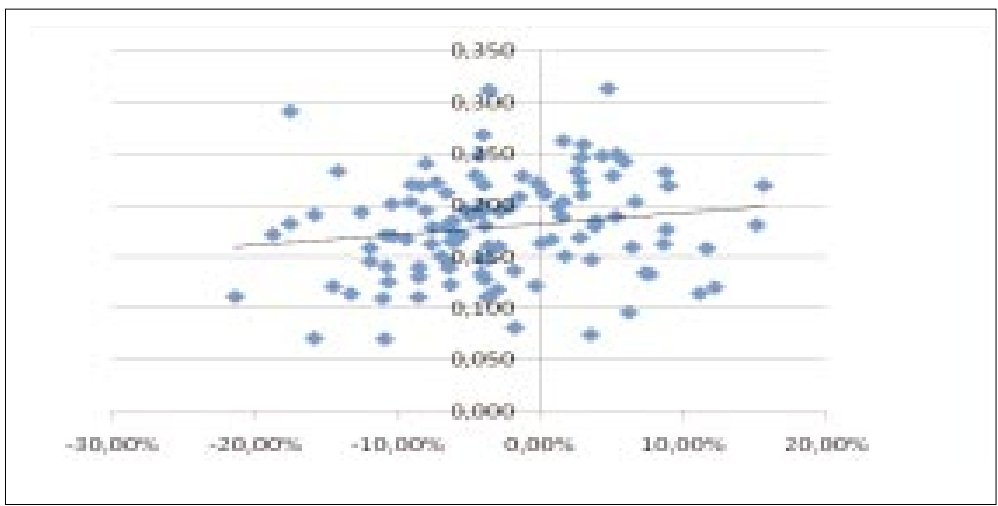

Fonte: IBGE; Processamento: NIPP.

\section{Vulnerabilidade social e o mundo rural}

Vamos nos restringir aqui a duas bases de dados que nos oferecem elementos para analisar a questão da vulnerabilidade familiar e comunitária. São eles o LAC ${ }^{17}$ e o Fasfil ${ }^{18}$. No LAC dispomos de dados sobre evasão rural e associativismo no período 2001-2003 cobrindo todas as unidades familiares rurais do estado. O Fasfil nos oferece informações sobre a densidade institucional tendo como substrato teórico o conceito de capital social. Buscamos o tratamento de evidências empíricas sobre ambas as dimensões pressupondo que uma maior articulação e agregação de interesses, intensificadas por uma rede de associações corporativas e comunitárias promove a colaboração social atuando na contramão da vulnerabilidade social, expressa aqui no fenômeno da evasão rural.

De acordo com o LAC, existem no estado 169.392 produtores rurais proprietários, sendo 136.733 com título de posse, $16.733 \mathrm{sem}$ o título de posse, 9.137 arrendatários, 2.022 parceiros e 4.767 são ocupantes. Cerca de 12.916 pessoas migraram nos 3 anos correspondentes ao período da pesquisa (2000-2003), sendo 6.175 homens e 6.454 mulheres. A proporção homens/mulheres foi de 1,05. Observou-se um baixo grau de desigualdade entre as microrregiões, mesmo assim os extremos ficaram entre Curitibanos $(1,52)$ e Maravilha $(0,88) .81,66 \%$ das pessoas que migraram no período, o fizeram dentro do estado. Neste universo, $41,59 \%$ foram para a sede do município, 45,78\% para municípios vizinhos ou da região e $12,63 \%$ para outras regiões do estado. Significa que $87,37 \%$ das pessoas migraram no âmbito da região. Cerca de $91,75 \%$ dos que migraram estavam na faixa de $10-19$ e 20-39 anos. As
${ }^{17}$ O Levantamento Agropecuário de Santa Catarina, publicado no início deste de 2005, apresenta em sua primeira versão, dados ainda preliminares. $\mathrm{O}$ censo abrangeu um universo de 230.157 estabelecimentos; sendo 172.786 estabelecimentos agropecuários em atividade, 161.749 na área rural. Neste artigo analisamos os dados agrupados por estado, município e SDR's (Secretarias de Desenvolvimento Regional)

${ }^{18}$ FASFIL (Fundações Privadas e Associações sem Fins Lucrativos no Brasil 2002) foi organizado pelo IBGE em parceria com o Instituto de Pesquisa Econômica Aplicada (IPEA) e a Associação Brasileira de Organizações Não-Governamentais (ABONG). 

mais industrializadas (Joinville, Blumenau, São Jose, Jaraguá do Sul, Brusque), provavelmente porque foram regiões que mais atraíram o fluxo.

Os principais motivos que levaram as pessoas migrarem foram: baixa rentabilidade da atividade agropecuária $(20,4 \%)$, estudar $(16,9 \%)$, matrimônio (13,4\%), busca de maior qualidade de vida na cidade $(13,2 \%)$ e busca de maior renda em outra atividade (9,3\%). Com exceção do matrimônio, as outras respostas estão vinculadas direta ou indiretamente à oferta de serviços públicos. Desta forma, podemos verificar a importância da oferta de serviços públicos como um meio de fornecer aos indivíduos possibilidade de superar um quadro de vulnerabilidade e construírem perspectivas futuras melhores referentes às condições de vida, sem a necessidade de deixar os seus locais de residência.

A baixa rentabilidade da propriedade, razão clássica de evasão rural foi o fator preponderante e o grande destaque se dá para Concórdia, seguida de outras regiões do Oeste catarinense. Estudar foi o segundo maior fator, sendo que em Xanxerê superou o fator rentabilidade da propriedade e, em Videira e Ituporanga estudar estava bem próximo do principal motivo para migrar. Levantamos a hipótese de que estes fatores estão conjugados, isto é, emigrar devido à baixa rentabilidade e ao mesmo tempo estudar, como por outro lado poderíamos constatar a ausência de estabelecimentos de ensino de nível médio, particularmente para atender os jovens, segundo maior grupo etário que migra.

É mais diversificando o quadro ramo onde foi atuar, entre as microrregiões. Se em Concórdia o trabalho na indústria foi o principal atrativo, em São Miguel do Oeste foi trabalho no comércio ou serviço. No primeiro item pressupomos um relativo grau de qualificação, enquanto que no segundo esta condição é mais fraca. O terceiro item outra atividade revela que existe uma multiplicidade de fatores de atração não previstos na pesquisa ou que não são convencionais nos fluxos migratórios. Aqui caberia aprofundar índices de qualificação escolar e gênero para compreender melhor esta diferenciação.

Observa-se que os quatro principais motivos de evasão (baixa rentabilidade, estudar, busca de maior renda em outra atividade e matrimônio) está igualmente entre os mais fortes nas regiões de Concórdia e São Miguel do Oeste. Igualmente estas duas regiões são as que apresentam o maior acervo de instituições do Oeste catarinense.

Considerando o universo de pesquisa do LAC, foram computados 160.811 vínculos associativos. Consideramos a expressão vínculos porque, provavelmente os entrevistados possam ter apontado mais de 
um vínculo, isto é, as associações não excludentes. As associações referidas foram: Cooperativa, Sindicato dos Trabalhadores Rurais, Sindicato Rural, Associação de Agricultores, Associação de Mulheres, Grupo de Comercialização, Grupo de Compra de Insumos, Condomínios de Produção, Grupo de Jovens, Clube Social, Clube de Mães, entre outros. Sindicatos dos Trabalhadores Rurais e as Cooperativas são os mais expressivos.

Os sindicatos dos trabalhadores rurais são predominantes em quase todas as regiões, particularmente em São Miguel do Oeste. Já em Concórdia o mesmo compete com cooperativa e em Chapecó, São Lourenço do Oeste e Xanxerê estas predominam. O que chama a atenção é a forte presença de clubes de mães. Principalmente em São Miguel do Oeste, Palmitos e Concórdia.

De acordo com o banco de dados Fundações Privadas e Associadas Sem Fins Lucrativos (FASFIL) entre 1996 e 2002, o número de entidades sem fins lucrativos cresceu de 105 mil para 276 mil entidades no país. Essa ampliação, de 169 mil novas organizações, correspondeu a um crescimento de $157 \%$ no período. Apesar de este crescimento ter sido verificado em todas as áreas de atuação, merecem destaque meio ambiente e desenvolvimento e defesa de direitos que quadruplicaram o número de entidades $(309 \%$ e $303 \%$, respectivamente), e as associações patronais e profissionais que mais do que triplicaram (252\%). ${ }^{19}$ Outro grupo a destacar foi o das organizações profissionais e patronais, que representa $16 \%$ das FASFIL inclui como subgrupo as associações de produtores rurais (56\%), sendo $34 \mathrm{mil}$ (76\%) criadas a partir de 1991. As FASFIL que se dedicam a ações culturais e recreativas correspondem a $14 \%$ do total e estão mais concentradas em entidades esportivas e de recreação do que em atividades culturais e artísticas. É no Sul do país que essas entidades são relativamente mais numerosas. As organizações que atuam, prioritariamente, na área de assistência social representam 12\% das FASFIL. Estão aqui incluídas as entidades voltadas para o atendimento de grupos específicos da população (crianças, adolescentes infratores, idosos, pessoas com deficiência, dentre outros). ${ }^{20}$

Santa Catarina possui 17.169 fundações e entidades sem fins lucrativos, o que corresponde a 6,2\% do montante do país. Quanto ao grupo de entidades os maiores destaques estão entre as entidades com perfis mais convencionais como cultura e recreação, assistência social e religião. É interessante observar que, onde havia maior número de entidades (cooperativas e sindicatos), também foi onde houve as maiores taxas de evasão rural, em São Miguel do Oeste e Concórdia. Duas hipóteses aqui se expressam: as regiões onde há maior evasão rural são
${ }^{19}$ Oficialmente $62 \%$ das instituições hoje existentes foram criadas a partir dos anos de 1990, ou seja, em 2002. $77 \%$ delas, não têm qualquer empregado. Levanta-se a hipótese de que parcela significativa dos serviços prestados por estas organizações é realizada por meio de trabalho não-remunerado, isto é, voluntário. $26 \%$ das FASFIL dedica-se diretamente a atividades confessionais seguidas de promoção do desenvolvimento e defesa de direitos $(16 \%)$, a maior parte delas (76\%) criada depois de 1990.

${ }^{20}$ Neste grupo de dados não estão computadas as cooperativas, consideradas entidades com fins lucrativos. 

rio e, b) As instituições foram suficientemente fortes para conter $87,37 \%$ do fluxo migratório no âmbito regional.

Outro dado importante oferecido pelo LAC remete à questão da comunidade. Dois aspectos merecem destaque. Perguntados sobre a quem recorrem quando necessitam de ajuda 73,3\% dos responsáveis pela unidade familiar responderam que recorrem aos vizinhos e 20,68\% buscam parentes . É interessante observar que instituições citadas como igreja, amigos, políticos e outros não somam 3\% das respostas. $\mathrm{Na}$ sequência foi perguntado sobre se aumentou ou diminui a confiança na comunidade nos três últimos anos. 73,23 dos entrevistados afirmaram que diminuiu a confiança nas pessoas da comunidade; para 13,09\% a confiança continua a mesma e para $12,33 \%$ ela aumentou. O índice mais forte de redução de confiança na comunidade foi em Rio do Sul $(83,99 \%)$ e Mafra $(83,93 \%)$; os índices menores aconteceram em Caçador $(63,16 \%)$. Estamos, portanto, diante de um dilema, por um lado o sentimento de proteção restrito à comunidade e, por outro a deterioração do sentimento comunitário. ${ }^{21}$

${ }^{21} \mathrm{O}$ questionário do LAC não indica as razões da perda de confiança.

\section{Considerações finais}

Sem querer esgotar as questões aqui levantadas e sim, sugerindo seu aprimoramento metodológico vamos destacar como resultado deste artigo três aspectos.

Em primeiro, a necessidade de ampliar o debate sobre indicadores de vulnerabilidade rural, buscando a) definições epistemológicas a respeito do que seja vulnerabilidade social no mundo rural e como poderiam ser expressas na forma de indicadores e, b) sugerir bases de dados para que pesquisas possam ser ampliadas.

No que se refere à oferta de serviços públicos reunimos variáveis que sinalizam tamanho e idade do município como recortes analíticos e que explicam um padrão de oferta destes serviços. Primeiramente, entre as 3 áreas aqui trabalhadas destacam-se aquelas cujas políticas públicas têm controle ou suporte da União, como educação e saúde, ao mesmo tempo a fragilidade e deficiência no campo do saneamento. Um segundo aspecto que deve ser aqui considerado são as condições institucionais e administrativas por tamanho dos municípios, como o diferencial partidos políticos no poder; um estudo sobre elites locais e um corpo de expertise disponível, cujas capacidades podem influenciar no resultado de implementação de políticas públicas. Finalmente, de- 
vemos considerar os serviços públicos oferecidos no âmbito do mercado, estudo que ainda merece atenção de pesquisa e que poderá explicar o perfil dos municípios em função de sua renda per capita.

Quanto à vulnerabilidade social rural, os dados indicaram, a partir do fenômeno da evasão rural que, além da baixa renda da propriedade rural, a ausência de oportunidades de estudo para jovens pressiona a decisão pela evasão. Sugerimos que outros aspectos, não tratados aqui como envelhecimento populacional e desigualdade de gênero podem ampliar a percepção sobre os fatores de vulnerabilidade social rural. No que diz respeito à comunidade vimos que a perspectiva de ajuda limitada à família e à comunidade, ao mesmo tempo em que esta vem sofrendo um processo de desconfiança revelam a ausência de aporte institucional e de políticas públicas.

\section{Referências}

CASTEL, ROBERT. As transformações da questão social. In: BELFIOREWANDERLEY, Mariângela; BÓGUS, Lucia; YASBEK, Maria Carmelita (Orgs.). Desigualdade e questão social. 2. ed. rev. e ampl. São Paulo, 2004. p. $235-165$.

KOVARICK, Lúcio. Sobre a vulnerabilidade socioeconômica e civil: Estados Unidos, França e Brasil. Rev. Brás. Ci. Soc., São Paulo, v. 18, n. 51, fev. 2003.

MATTOS MONTEIRO, Felipe. Estudo comparativo da oferta de serviços públicos em Santa Catarina. 2006. Trabalho de Conclusão de Curso (bacharelado em Ciências Sociais) - Universidade Federal de Santa Catarina, Florianópolis, 2006.

MELO, Marcus André. Crise federativa, guerra-fiscal e hobbesianismo municipal: as vicissitudes da descentralização. Perspectiva, São Paulo, v. 10, n. 3, p. 1$14,1996$.

SEIBEL, Erni. J. A redefinição do conceito "offeano" de seletividade diante de uma conjuntura globalizada. Organizações e Sociedade, Salvador, BA, v. 8, n. 20 , p. $73-80,2001$.

. O declínio do welfare state e a emergência do estado prisional. Tempos de um novo puritanismo? Civitas, Porto Alegre, v. 5, n. 1, p. 93-107, 2005.

SOUZA, Celina. Federalismo, desenho constitucional e instituições federativas no Brasil pós-1988. Rev. Sociol. Politic., n. 24, p. 105-121. 

2001.

WANDERLEY, Maria de Nazareth Baudel. A ruralidade no Brasil moderno. Por um pacto social pelo desenvolvimento rural. In: Una nueva ruralidad en América Latina?, 2000.

\begin{abstract}
In this study we intend to examine social vulnerability and the provision of public services in rural areas. The process of globalization has produced a reallocation of the provision of basic public services (mainly education, health and sanitation) between the agents involved (state and market) introducing selective, precarious and exclusionary access to those services, (re)producing areas of vulnerability. Social vulnerability involves the weakening of the family structure, community and institutions, to external threats, technological and informational complexity, ability to stay in the market, imbalance in gender relations, population aging, among others. The provision of public services is marked by its absence or its concentration in urban areas, especially those directed at protecting family and community, such as health and education (the most requested), communication, and sanitation. The database was formed from the Population Census and Agricultural Census (IBGE) and the LAC (Agricultural Survey/SC). The survey results showed that the mountainous regions and northern Santa Catarina are the most fragile in relation to provision of public services. However, the regions of Vale do Itajaí, greater Florianópolis and southern Santa Catarina present a greater regional balance in spite of sanitation in these areas being 'fragile' at best. Considering the association between IOSP/Basic demographic variation and found that those cities with a good rate of supply of public services experienced positive change in the population. It is possible to highlight a growing weakness in rural communities, with a growing distrust between the residents associated with the negative sentiment of institutional support in the case of social protection.
\end{abstract}

Keywords: social vulnerability, public services, rural territories. 